\title{
ROLE OF SUSTAINABLE TECHNIQUES IN MANUFACTURING PROCESS: A REVIEW
}

\author{
Rajeev Sharma ${ }^{*}{ }^{\otimes}$, Binit Kumar Jha ${ }^{2}$, Vipin Pahuja ${ }^{3}$ \\ *1, 2, 3 School of Manufacturing Skills, Bhartiya Skill Development University, Jaipur, India
}

DOI: https://doi.org/10.29121/ijetmr.v8.i2.2021.869

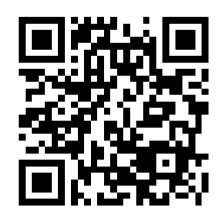

Article Citation: Rajeev Sharma, Binit Kumar Jha, and Vipin Pahuja. (2021). ROLE OF SUSTAINABLE TECHNIQUES IN MANUFACTURING PROCESS: A REVIEW. International Journal of Engineering Technologies and Management Research, 8(2), 41-45.

https://doi.org/10.29121/ijetmr.v8 i2.2021.869

Published Date: 17 February 2021

Keywords:

Sustainable Machining

Cryogenic Machining

MQL

Dry Machining

Duplex Stainless steel

\begin{abstract}
Customary mineral based liquids are as a rule broadly utilized in cooling and greases in machining activities. Nonetheless, these cutting liquids are the suitable wellspring of numerous natural and organic issues. To kill the evil impacts related with cutting liquids, it is important to move towards practical machining methods. Such sustainable machining techniques utilize minimize the amount of cutting liquid, fluid nitrogen, vegetable oil or packed air as a cooling-oil medium. The liquids utilized in economical machining strategies are viewed as absolutely biodegradable and Eco-friendly. This paper is a careful survey of the relative multitude of current environmental friendly machining methods as of now rehearsed in the metal cutting cycle. It has been likewise discovered that these economical machining strategies more often than not give better outcomes as far as improved surface nature of the machined part, upgraded apparatus life, less cutting temperatures and slicing powers when contrasted with traditional wet machining techniques. The principle motivation behind this survey work is to recognize the diverse supportable strategies and empower the utilization of such procedures in metal machining, so that, the reducing interaction turns out to be more expense powerful and climate inviting.
\end{abstract}

\section{INTRODUCTION}

Environment friendly machining is the latest pattern in the present modern climate. In this both monetary just as ecological advantages. The need of moving towards environmental friendly machining technique is because of a few elements like increment of word related illnesses among the specialists on the shop floor, severe administrative arrangements with respect to climate, and a requirement for decrease in by and large expense during assembling [1]. The Metal cutting operation is the most generally utilized modern practice for which feasible manufacturing is a suitable methodology. Today's, because. of the ecological concerns, developing defilement and contamination guidelines, the interest for inexhaustible and biodegradable cutting liquids are expanding [2]. In machining, broad measure of metal working fluids (MWFs) has been utilized for oil and cooling approaches [3]. The vast majority of these customary MWFs are set up from the non manageable unrefined petroleum separates [4]. It is assessed that a sum of 640 million gallons of MWFs is every year burned-through all through the world [5]. The assessed yearly use of MWFs by European Union is around 320,000 tones, out of which 66 percent is arranged after utilized [6]. By and large expense of upkeep to removal and word related sicknesses brought about by such uncontrolled uses are the significant downsides related with use of MWFs. The expense of putting away and removal of cutting liquid is

(C) 2021 The Author(s). This is an open access article distributed under the terms of the Creative Commons Attribution License, which permits unrestricted use, distribution, and reproduction in any medium, provided the original author and source are credited. 
multiple times higher than that of absolute machining cost. This expense can represent about $17 \%$ of the absolute expense for car components [7]. Detailed information demonstrates that $80 \%$ of word related skin sicknesses are brought about by cutting liquids [8]. The examination by [9] proposes that MWFs are the reason for respiratory and skin illnesses among the mechanical engineers. Public Institute of Occupational Safety and Health (NIOSH) announced that more than 1 million laborers are affected by toxicology impacts brought about by cutting liquids. The most noteworthy grouping of these cutting liquids is the likely reason for chest bronchitis and skin problem. Thusly, it is significant from the expense and wellbeing perspective to annihilate or generously decrease the utilization of MWFs. According to [10] dry machining process is environment friendly machining because in this process no air and water pollution. The environment friendly machining means that machining process in which reduction of harmful wastes [11]. Also, dry machining approach is one such process in which can be carried out in the without of cutting fluid and thus is a more sustainable method compared to conventional wet machining process [12]. In Sustainable machining process less coolant cost and satisfactory process compared to other process which as shown in Figure 1.

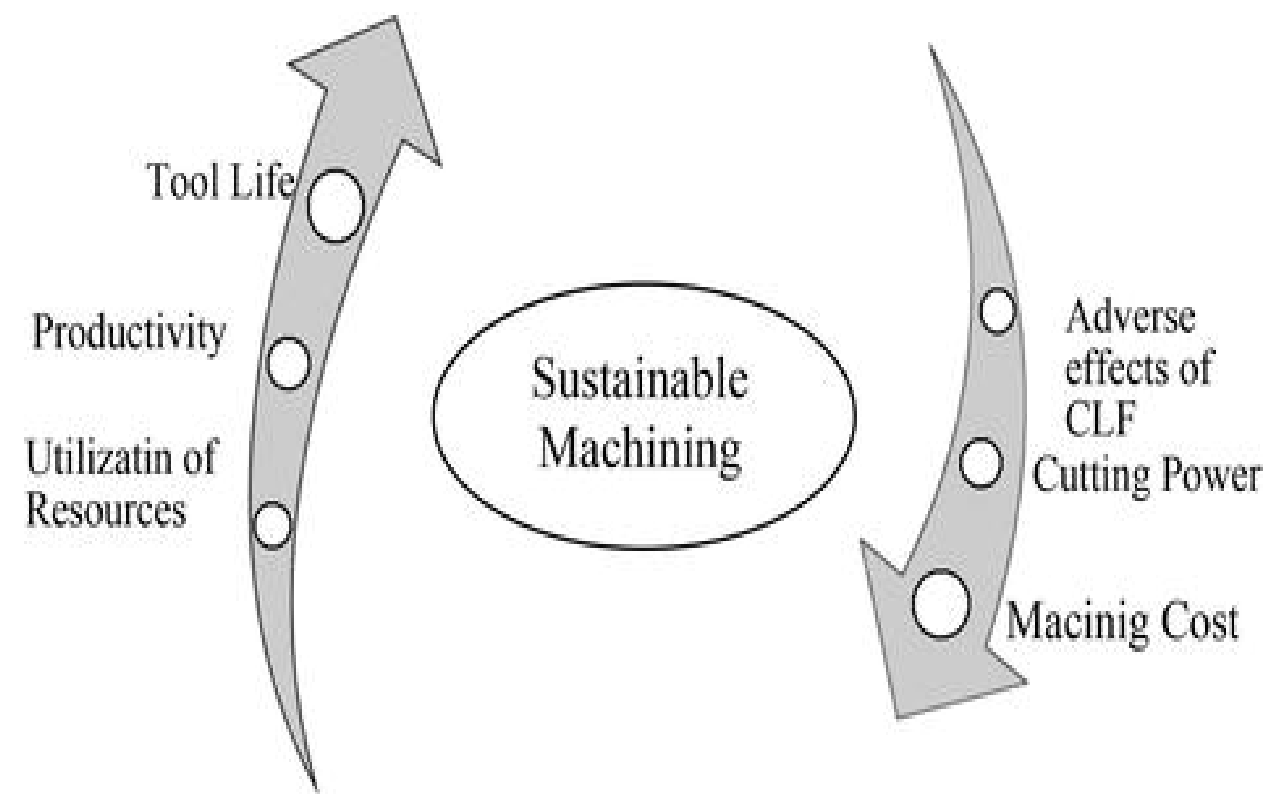

Figure 1: Layout of Sustainable Machining

\section{LITERATURE SURVEY}

In this paper literature survey on sustainable machining process. Cryogenic machining is sustainable machining process which compared with the different cooling environment for analysis the tool life, Tool wear, surface roughness, cutting force, chop morphology and cutting temperature of work piece after these analysis results found that sustainable machining provide better machinability compared to other [13]. Some Literature surveys are following.

\begin{tabular}{|c|c|}
\hline Author Name & Research Out-Come \\
\hline $\begin{array}{c}\text { Kumar, U., Senthil, P. } \\
\text { (2019) [14] }\end{array}$ & $\begin{array}{c}\text { In this research article, research works carried on Ti-6Al-4V under } \\
\text { different cooling environments e.g. dry (untreated condition) and } \\
\text { cryogenic treated condition (12H, 24H, and 36H). After the experimental } \\
\text { investigation it was found that the Deep cryogenic treated up to 36h is } \\
\text { most effective \& reduced tool wear compared to other. }\end{array}$ \\
\hline $\begin{array}{c}\text { Wika, K.K., Gurdal, 0. } \\
\text { et.al (2019) [15] }\end{array}$ & $\begin{array}{c}\text { This paper deals with experimental work on Ti-6Al-4V under flood } \\
\text { cooling, super critical CO2 and Super critical CO2 with MQL. After this } \\
\text { investigation result found that 163\% improve tool life with ScCo2+MQL } \\
\text { at V-60, f-0.5mm/tooth. }\end{array}$ \\
\hline Periyasamy, R., & \\
\hline
\end{tabular}




\begin{tabular}{|c|c|}
\hline $\begin{array}{l}\text { Gopinath, V. et.al ( } \\
\text { 2020) [16] }\end{array}$ & $\begin{array}{l}\text { In this paper machining work completed on SS310 with Untreated insert } \\
\text { and cryogenic cooling inserts. The results show that Cryogenic treated } \\
\text { HSS drill bit has improved the Ra, minimizes the diameter error. }\end{array}$ \\
\hline $\begin{array}{c}\text { Sun, Y., Puleo, } \\
\text { D.A. et.al (2016) [17] }\end{array}$ & $\begin{array}{l}\text { Experimental investigation on Ti-6Al-7Nb under different cooling } \\
\text { environment such as dry, flood coolant and cryogenic cooling } \\
\text { Environment. After research work it was found that CF and thrust force } \\
\text { reduction by } 30 \% \text { compared to machining with MQL, flood. }\end{array}$ \\
\hline $\begin{array}{l}\text { Ravi, S., Gurusamy, P. ( } \\
\text { 2020) [18] }\end{array}$ & $\begin{array}{l}\text { This paper deal with machining on AISI P20 under different cooling } \\
\text { environment such as dry, flood and cryogenic cooling environment. } \\
\text { After this experimental research work found that 15-17\% reduction of } \\
\text { tool wear by using cryogenic compared to dry, flood cooling, and also } \\
\text { Chip curl by a reduction chip temperature in cryogenic cooling system. }\end{array}$ \\
\hline Ozbek, N.A. ( 2020) [19] & $\begin{array}{l}\text { In this research article, experimental work completed on AISI H11under } \\
\text { dry and cryogenic cooling (UT, SCT6, DCT6, DCT24). After this research } \\
\text { work, result was found that DCT } 24 \text { provide significance result for Ra, } \\
\text { flank wear, micro hardness. }\end{array}$ \\
\hline $\begin{array}{l}\text { Dhananchezian, M., } \\
\text { Priyan, M.R. et.al (2017) } \\
{[20]}\end{array}$ & $\begin{array}{c}\text { In this research article, research work completed on duplex stainless } \\
\text { steel } 2205 \text { under dry machining condition and cryogenic cooling } \\
\text { condition. As a results, the reduction in cutting temp. And cutting force } \\
\text { respectively 53-58\%, 30-43\%. And roughness was rises } 18-23 \% \\
\text { compared to dry machining. }\end{array}$ \\
\hline $\begin{array}{c}\text { S.K. Khare, Agarwal, S. ( } \\
\text { 2017) [21] }\end{array}$ & $\begin{array}{c}\text { In this paper experiment carried out on work piece of AISI } 4340 \text { steel } \\
\text { with cryogenic cooling machining process. After this experimental } \\
\text { investigation found that the error in this with Ra is only } 5.32 \% \text {. And also } \\
\text { observed V and } d \text { is more effective parameters. }\end{array}$ \\
\hline $\begin{array}{l}\text { Nie, G.C., Zhang, X.M. } \\
\text { et.al ( 2018) [22] }\end{array}$ & $\begin{array}{l}\text { In this Paper research work carried out on AISI } 52100 \text { steel work piece } \\
\text { with dry environment machining and cryogenic cooling environment } \\
\text { machining. After machining result was found that the cryogenic } \\
\text { machining provide best result compared to dry machining. }\end{array}$ \\
\hline Vakkas, C. (2019) [23] & $\begin{array}{l}\text { This paper describes machining on Inconel } 625 \text { under different cooling } \\
\text { environment such as Dry, Pure MQL, LN2, Nmql, cry-MQL, Cry-Nmql. } \\
\text { After the experiment results it was found that } 0.5 \text { vol. \% hbn cooling } \\
\text { method used with LN2 and provide the best results in terms of } \\
\text { Machining performance e.g. tool life, Ra etc. }\end{array}$ \\
\hline $\begin{array}{l}\text { Sivalingam, V., Sun, J., } \\
\text { Yang, B. et.al ( 2018) } \\
\text { [24] }\end{array}$ & $\begin{array}{l}\text { Experimental investigation on Ti-6Al-4V under untreated condition and } \\
\text { treated conditions }(24 \mathrm{H}, 48 \mathrm{H}) \text {. As a result, } 48 \mathrm{H} \text { give most favorable } \\
\text { results and reduced the Vibrations compared to untreated, } 24 \mathrm{H} \text {. }\end{array}$ \\
\hline $\begin{array}{l}\text { Pu, Z., Quteriro, J.C., } \\
\text { Batista, A.C. et.al ( 2012) } \\
\text { [25] }\end{array}$ & $\begin{array}{l}\text { In this paper experimental investigation on AZ31 B mg alloy with dry } \\
\text { machining and cryogenic cooling environment. This paper suggests that } \\
\text { cryogenic machining may also enhance the surface integrity of } \mathrm{W} / \mathrm{p} \text { and } \\
\text { improve the machining performance. }\end{array}$ \\
\hline $\begin{array}{l}\text { Chetan, Ghosh, S., Rao, } \\
\text { P.V. ( 2019) [26] }\end{array}$ & $\begin{array}{l}\text { In this paper studied on NiTi alloy under different cooling environment } \\
\text { such as dry machining, MQL machining and cryogenic cooling (LN2). it is } \\
\text { observed that cryogenic machining provide significance result compared } \\
\text { to dry machining, MQL. }\end{array}$ \\
\hline
\end{tabular}

\section{CONCLUSION}

The writing survey demonstrated that the Cryogenic Lubrication gives gigantic applications in the metal eliminating measures. Based on the above writing talked about, it has been coming to a limited extent that the cryogenic is a way extraordinary methodology where the temperature in the slicing territory is diminished to very low reach. It is additionally seen that from the above work, cryogenic oil is the most fitting response to eco- 
accommodating machining at higher cutting speeds. Cryogenic Refrigeration is the awesome flawless innovation that is eco-accommodating to accomplish the ideal control of the warmth of the cutting and most extreme existence of the instrument.

\section{SOURCES OF FUNDING}

This research received no specific grant from any funding agency in the public, commercial, or not-for-profit sectors.

\section{CONFLICT OF INTEREST}

The author have declared that no competing interests exist.

\section{ACKNOWLEDGMENT}

None.

\section{REFERENCES}

[1] Jayal, A.D., Badurdeen, F., Dillon Jr., O.W., Jawahir, I.S., 2010. Sustainable manufacturing: modeling and optimization challenges at the product, processand system levels. CIRP J. Manuf. Sci. Technol. 2, 144e152.

[2] R. Sharma, Binit Kumar Jha and V. Pahuja, Impact of environmental friendly machining on machinability: A review, Materials Today: Proceedings, https://doi.org/10.1016/j.matpr.2020.12.498.

[3] Abdalla, H.S., Patel, S., 2006. The performance and oxidation stability of sustainable metal working fluid derived from vegetable extracts. Proc. Inst. Mech. Eng. Part B: J. Eng. Manuf. 220, 2027e2040.

[4] Pusavec, F., Krajnik, P., Kopac, J., 2010a. Transitioning to sustainable production e Part I: application on machining technologies. J. Clean. Prod. 18, 174e184.

[5] Brockhoff, T., Walter, A., 1998. Fluid minimization in cutting and grinding: abrasives. J. Abras. Eng. Soc. Butl. $38 \mathrm{e} 42$.

[6] Abdalla, H.S., Baines, W., McIntyre, G., Slade, C., 2007. Development of novel sustainable neat-oil metal working fluids for stainless steel and titanium alloy machining. Part 1. Formulation development. Int. J. Adv. Manuf. Technol. 34, 21e33.

[7] Marksberry, P.W., 2007. Micro-flood (MF) technology for sustainable manufacturing operations that are coolant less and occupationally friendly. J. Clean. Prod. 15, 958e971.

[8] Lawal, S.A., Choudhury, I.A., Nukman, Y., 2012. Application of vegetable oil-based metalworking fluids in machining ferrous metalsdA review. Int. J. Mach. Tools Manuf. 52, $1 \mathrm{e} 12$.

[9] Hannu, T., Suuronen, K., Aalto-Korte, K., Alanko, K., Luukkonen, R., J€arvel€a, M., Jolanki, R., Jaakkola, M., 2013. Occupational respiratory and skin diseases among Finnish machinists: findings of a large clinical study. Int. Arch. Occup. Environ. Health 86, 189e197.

[10] Dixit, U.S., Sarma, D.K., Davim, J.P., 2012. Environmentally Friendly Machining, First ed. Springer, New York, USA.

[11] Obi, S.C., 2013. Introduction to Manufacturing Systems, First ed. Author House, Bloomington, USA.

[12] Schultheiss, F., Zhou, J., Gr€ontoft, E., Ståhl, J.-E., 2013. Sustainable machining through increasing the cutting tool utilization. J. Clean. Prod. 59, $298 \mathrm{e} 307$.

[13] Rajeev Sharma et al 2020 IOP Conf. Ser.: Mater. Sci. Eng. 998012013.

[14] U. Kumar, P. Senthil, A comparative machinability study on titanium alloy Ti- 6Al-4V during dry turning bt cryogenic treated and untreated condition of uncoated WC inserts, Mater. Today Proc. (2019) 2214-7853.

[15] K.K. Wika, O. Gurdal, P. Litwa, C. HitchensC.,, Influence of supercritical CO2 cooling on tool wear and cutting force in the milling of Ti-6Al-4V, Procedia CIRP 82 (2019) 89-94.

[16] R. Periyasamy, V. Gopinath, G. Selvakumar, R.A. Kingsslly, S. Logeshwaran, (2020). Evalution of the effect of cryogenic treatment of HSS drills in drilling SS310. Mater. Today Proc. 
[17] Y. Sun, D.A. Puleo, J. Schoop, I.S. Jawahir, Improved surface integrity from cryogenic machining of Ti- $6 \mathrm{Al}-7 \mathrm{Nb}$ alloy for biomedical application, Procedia CIRP 45 (2016) 63-66.

[18] S. Ravi, P. Gurusamy, (2020). Experimental investigation on performance of TiN and TiAlN coated tools in cryogenic milling of AISI D2 hardened steel. Mater. Today Proc.

[19] N.A. Ozbek, (2020). Effect of cryogenic treatement types on the performance of coated tungsten tools in the turnining of AISI H11 steel. J. Mater. Res. Technol.

[20] M. Dhananchezian, M.R. Priyan, G. Rajashekar, S.S. Narayanan, Study the effect of cryogenic cooling on machinability characteristics during turning duplex stainless steel 2205, Mater. Today Proc. 5 (2017) 1206212070.

[21] S.K. Khare, S. Agarwal, Optimization of machining parameters in turning of AISI 4340 steel under cryogenic condition using Taguchi technique, Procedia CIRP 63 (2017) 610-614.

[22] G.C. Nie, X.M. Zhang, D. Zhang, H. Ding, An experimental study of the white layer formation during cryogenic assisted hard machining of AISI 52100 steel, Procedia CIRP 77 (2018) 223-226.

[23] C. Vakkas, Experimental comparison of the performance of nano fluids, cryogenic and hybrid cooling in turning of inconel 625, Tribol. Int. 137 (2019) 366-378.

[24] V. Sivalingam, J. Sun, B. Yang, K. Liu, R. Raju, Machining performed and tool wear analysis on cryogenic treated inserts during end milling of Ti-6Al-4V alloy, J. Manuf. Processes 36 (2018) 188-196.

[25] Z. Pu, J.C. Outeiro, A.C. Batista, O.W. Dillon, D.A. Puleo, I.S. Jawhar, Enhanced surface integrity of AZ31B Mg alloy by cryogenic machining towards improved functional performance of machined components, Int. J. Mach. Tools Manuf. 56 (2012) 17-27.

[26] S. Chetan, P.V. Ghosh, P.V. Rao, Comparison between sustainable cryogenic techniques and nano-MQL cooling mode in turning of nickel- based alloy, J. Cleaner Prod. 231 (2019) 1036-1049. 